\title{
The Pumilio-domain protein PUF6 contributes to SIDER2 retroposon-mediated mRNA decay in Leishmania
}

\author{
HIVA AZIZI, ${ }^{1,2}$ CAROLE DUMAS, ${ }^{1,2}$ and BARBARA PAPADOPOULOU ${ }^{1,2}$ \\ ${ }^{1}$ Research Center in Infectious Diseases, CHU de Quebec Research Center-Laval University, Quebec, QC, G1V 4G2 Canada \\ ${ }^{2}$ Department of Microbiology, Infectious Diseases and Immunology, Faculty of Medicine, Laval University, Quebec, QC, G1V 0A6 Canada
}

\begin{abstract}
Leishmania and other trypanosomatid protozoa lack control at the level of transcription initiation and regulate gene expression exclusively post-transcriptionally. We have reported previously that Leishmania harbors a unique class of short interspersed degenerate retroposons (SIDERs) that are predominantly located within $3^{\prime}$ UTRs and play a major role in post-transcriptional control. We have shown that members of the SIDER2 subfamily initiate mRNA decay through endonucleolytic cleavage within the second conserved 79-nt signature sequence of SIDER2 retroposons. Here, we have developed an optimized MS2 coat protein tethering system to capture trans-acting factor(s) regulating SIDER2-mediated mRNA decay. Tethering of the MS2 coat protein to a reporter RNA harboring two MS2 stem-loop aptamers and the cognate SIDER2-containing $3^{\prime} \mathrm{UTR}$ in combination with immunoprecipitation and mass spectrometry analysis led to the identification of RNA-binding proteins with known functions in mRNA decay. Among the candidate SIDER2-interacting proteins that were individually tethered to a SIDER2 reporter RNA, the Pumilio-domain protein PUF6 was shown to enhance degradation and reduce transcript half-life. Furthermore, we showed that PUF6 binds to SIDER2 sequences that include the regulatory 79-nt signature motif, hence contributing to the mRNA decay process. Consistent with a role of PUF6 in SIDER2-mediated decay, genetic inactivation of PUF6 resulted in increased accumulation and higher stability of endogenous SIDER2-bearing transcripts. Overall, these studies provide new insights into regulated mRNA decay pathways in Leishmania controlled by SIDER2 retroposons and propose a broader role for PUF proteins in mRNA decay within the eukaryotic kingdom.
\end{abstract}

Keywords: Leishmania; SIDER2 retroposons; MS2 coat protein tethering system; Pumilio proteins; PUF6; mRNA decay

\section{INTRODUCTION}

Leishmania spp. are unicellular eukaryotic pathogens causing a wide spectrum of pathologies in humans ranging from $\mathrm{cu}-$ taneous to visceral infections (Desjeux 2004). Leishmania has a digenetic life cycle alternating between extracellular promastigotes in the insect vector and amastigotes inside the phagolysosome of mammalian macrophages where they replicate and cause disease (Bates and Rogers 2004). Similarly to other trypanosomatids, the Leishmania genome is organized in long polycistronic units (Myler et al. 1999; Ivens et al. 2005). In the absence of transcriptional control by RNA polymerase II in trypanosomatids, polycistronic units are transcribed in a constitutive manner and further processed to mature mRNAs through a coordinated 5'-trans-splicing and 3 '-polyadenylation cleavage reactions (Papadopoulou et al. 2008; Michaeli 2011). In addition, gene expression has been shown to change dramatically throughout the complex life cycles of these parasites (Haile and Papadopoulou 2007; Rochette et al. 2008; Nilsson et al. 2010; Siegel et al.

Corresponding author: barbara.papadopoulou@crchul.ulaval.ca

Article is online at http://www.rnajournal.org/cgi/doi/10.1261/rna. 062950.117. Freely available online through the RNA Open Access option.
2010). Regulation of mRNA decay rates through interactions of RNA-binding proteins (RBPs) with cis-acting sequences in $3^{\prime}$ UTRs of trypanosomatid transcripts is central in determining the fate of mRNAs and thus fine-tuning developmental gene expression (McNicoll et al. 2005; Bringaud et al. 2007; Haile and Papadopoulou 2007; Haile et al. 2008; Müller et al. 2010b; Kramer 2012; Clayton 2013). Several RBPs, such as zinc finger proteins, Alba-domain proteins, and Pumilio (PUF) proteins, have been found to regulate mRNA stability in trypanosomatids (Clayton 2013; Dupé et al. 2014).

The genomes of trypanosomatids contain a large repertoire of RBPs, few of which have been characterized to interact with specific sequences in $3^{\prime}$ UTRs. In Trypanosoma cruzi, UBP1 binds to an AU-rich RNA instability element (ARE) in the $3^{\prime}$ UTR of small mucin mRNAs and promotes RNA destabilization (D'Orso and Frasch 2001). In T. brucei, PUF9 binds to a consensus sequence in $3^{\prime}$ UTR of transcripts whose function is important in temporal coordination of the kinetoplast and nuclear replication during late S-phase (Archer et al.

(C) 2017 Azizi et al. This article, published in RNA, is available under a Creative Commons License (Attribution 4.0 International), as described at http://creativecommons.org/licenses/by/4.0/. 
2009). The T. brucei ZC3H11 binds to and stabilizes mRNAs encoding chaperones required for protein refolding following heat shock (Droll et al. 2013). DRBD3, a protein containing two RRM domains, plays a role both in splicing and mRNA stability in T. brucei (Estévez 2008; Das et al. 2012). Also, DRBD13 has been demonstrated to negatively regulate mRNAs encoding for cell membrane-associated proteins via interaction with AREs of the target transcripts (Jha et al. 2015). More recently, we showed that the Leishmania infantum Alba3 protein can stabilize the developmentally regulated amastin transcripts specifically in the amastigote stage upon binding to a U-rich element in the $3^{\prime}$ UTR (Dupé et al. 2014).

In Leishmania, we have previously identified a large family of extinct retroposon elements termed short interspersed degenerate retroposons (SIDERs) (>2000 copies per genome), predominantly located within $3^{\prime}$ UTRs (Bringaud et al. 2007, 2008; Smith et al. 2009). Members of the two major SIDER subfamilies were shown to regulate mRNA turnover in a stage- and species-specific manner (SIDER2 subfamily) (Bringaud et al. 2007; Rochette et al. 2008; Müller and Papadopoulou 2010; Müller et al. 2010a,b) or mRNA translation (SIDER1 subfamily) (Boucher et al. 2002; McNicoll et al. 2005), and possibly to form RNA regulons (Ouellette and Papadopoulou 2009; Smith et al. 2009). We showed that degradation of SIDER2-bearing transcripts is initiated by endonucleolytic cleavage (Müller et al. 2010b; Papadopoulou et al. 2015) as opposed to the default process in eukaryotes, which begins with poly(A) shortening by deadenylases followed by $5^{\prime}$ cap removal and $5^{\prime}-3^{\prime}$ degradation by the XRN1 exoribonuclease or $3^{\prime}-5^{\prime}$ degradation by the exosome (Schoenberg and Maquat 2012). Cleavage was mapped at AU/CU dinucleotides within the second tandem 79-nt hallmark sequence (signature II) (Müller et al. 2010a; Azizi et al. 2017b) that is conserved at the $5^{\prime}$-end of all SIDER2 retroposons but not SIDER1 (Bringaud et al. 2007; Smith et al. 2009). More recently, we showed that SIDER2-harboring mRNAs have to associate with translating ribosomes in order to be degraded (Azizi et al. 2017a), suggesting that the putative endoribonuclease and associated mRNA decay factors have to be recruited to the translation apparatus.

In this study, we followed up on the mechanism of SIDER2-mediated mRNA decay by searching for trans-acting factors regulating this process. To this end, we have developed a bipartite MS2 coat protein pull-down system to identify RNA-binding protein candidates bound specifically to a SIDER2-containing reporter RNA. In vivo UV-crosslinking and immunoprecipitation combined with LC-MS/MS studies allowed us to identify several candidate proteins bound to a SIDER2-harboring $3^{\prime}$ UTR but not to a $3^{\prime}$ UTR lacking SIDER2. Among the candidate RNA-binding proteins with known functions in mRNA decay, the Pumilio-family member (PUF6) was shown to enhance degradation and reduce transcript half-life upon tethering to SIDER2 regulatory sequences. Furthermore, we showed that genetic inactivation of PUF6 leads to an increased stability of endogenous SIDER2-bearing transcripts, supporting a role of PUF6 protein in the SIDER2-mediated mRNA decay process.

\section{RESULTS}

\section{Development of an improved MS2 coat protein tethering system for identifying trans-acting factors regulating SIDER2 retroposon-mediated $m R N A$ decay in Leishmania}

So far, the $\lambda \mathrm{N}$ peptide has been used successfully to tether RBPs to a particular RNA of interest in the related Trypanosoma species (Delhi et al. 2011; Wurst et al. 2012; Droll et al. 2013; Jha et al. 2014; Singh et al. 2014). Here, we have developed an improved MS2 coat protein tethering system adapted for use in Leishmania to attach RNA-binding proteins (RBPs) specifically to a reporter RNA. A schematic diagram describing this system is shown in Figure 1A. The bacteriophage MS2/R17, MS2 coat protein (MCP) recognizes and binds to a specific stem-loop aptamer termed MS2 stem-loop (MS2 SL) of the replicase open reading frame to suppress its translation (Bernardi and Spahr 1972). This observation was later applied successfully to many fields of RNA biology, including mRNA localization, capturing of ribonucleoprotein complexes, mRNA translation, and decay (KeryerBibens et al. 2008; Buxbaum et al. 2015). We used the mFold RNA secondary structure prediction software to determine the best flanking sequences required to form a MS2 stemloop structure. By testing different flanking sequence combinations, we were able to find the most suitable sequence allowing the tandem MS2 hairpin RNA to form in silico (Fig. 1B). Figure 1C displays four LUC-MS2 reporter constructs containing or not a SIDER2 element that were used in this study. In Saccharomyces cerevisiae, it was recently reported that binding of MCP to MS2 SL, inserted into 3'UTR of the genes encoding for QCR8 and PGK1RNA, blocked XRN1 $5^{\prime}-3^{\prime}$ exoribonuclease activity and led to the accumulation of $3^{\prime}$ mRNA fragments containing MS2 SLs (Garcia and Parker 2015). To ascertain that the insertion of two MS2 hairpin structures downstream from the $L U C$ gene and its interaction with MCP does not alter decay rates of the LUC-SIDER2 reporter transcripts, we compared MS2-LUC-4000 3'UTR along with the non-MS2 RNA, LUC-4000 3'UTR by Northern blot hybridization (Fig. 1D). As we have reported previously, SIDER2 retroposon promotes rapid RNA decay, whereas deletion of SIDER2 from the $3^{\prime}$ UTR blocks degradation and causes accumulation of the LUC reporter mRNA (Fig. 1D; Bringaud et al. 2007; Müller et al. 2010b). Here, we show that addition of two MS2 hairpins in the reporter RNA and binding to MCP does not alter degradation by SIDER2 (Fig. 1D). Furthermore, we improved the MS2 pull-down system by optimizing expression levels of MCP. A single copy of MCP was not expressed sufficiently when transfected into L. infantum (data not shown). In the absence 
A

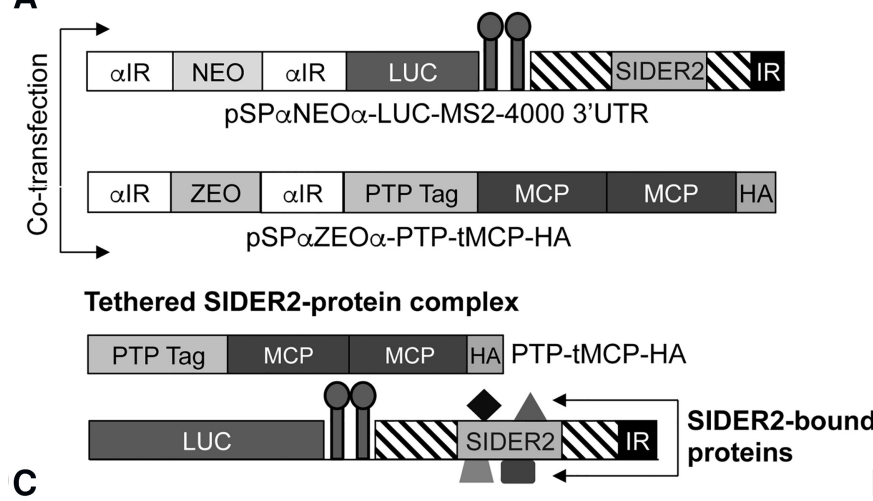

C

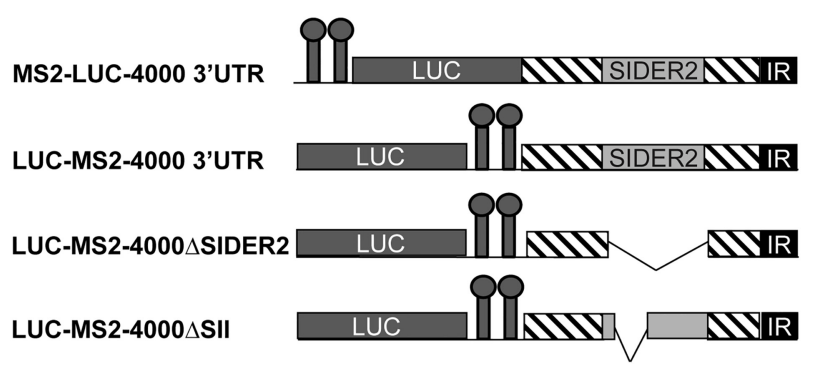

B

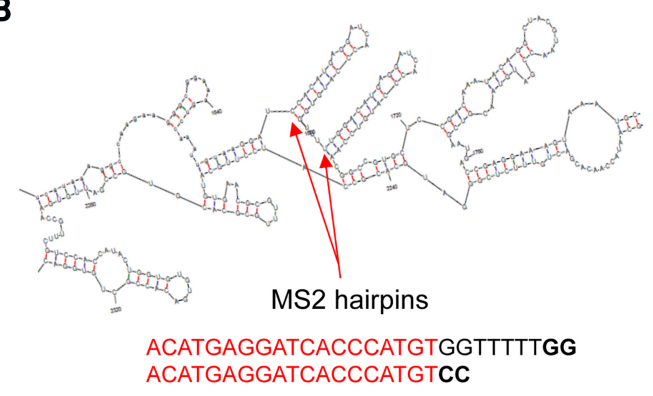

E

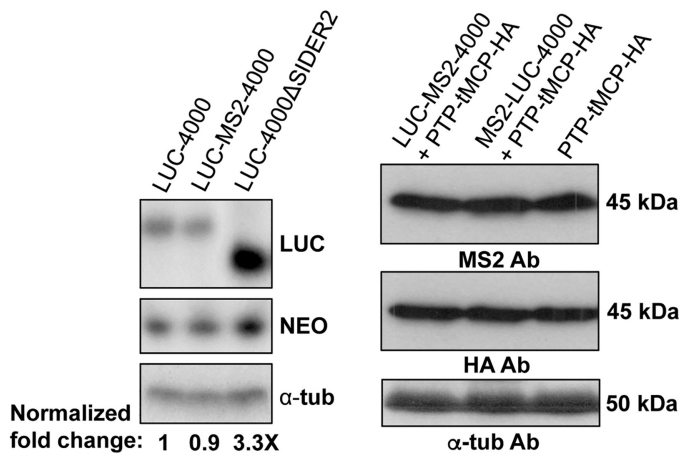

FIGURE 1. Schematic representation of the MS2 coat protein tethering system optimized and adapted for use in Leishmania. (A) This bipartite system consists of two vectors cotransfected into L. infantum: the first (pSPaZEOa-PTP-tMCP-HA) expressing two tandem ( $\mathrm{t}$ ) copies of the bacteriophage MS2 coat protein (MCP) with a PTP-tag at the N terminus and a HA-tag at the C terminus; and the second (pSPaNEOaLUC-MS2-4000 $\left.3^{\prime} \mathrm{UTR}\right)$ a luciferase $(L U C)$ reporter gene whose expression is driven by a SIDER2-harboring $3^{\prime} \mathrm{UTR}\left(3^{\prime} \mathrm{UTR}\right.$ of the $L$. infantum LinJ.36.4000 transcript harboring a SIDER2 element) and two MS2 hairpins. $\alpha$ IR, intergenic region of the $\alpha$-tubulin gene allowing trans-splicing and polyadenylation; NEO, neomycin phosphotransferase gene; ZEO, zeocin gene for plasmid selection following transfection. Two MS2 hairpins and a tandem MCP dimer were used to optimize binding affinity of MCP to MS2 RNA. Binding of MCP to the MS2 hairpins also tethers proteins specifically interacting with the SIDER2 RNA that can be identified by coimmunoprecipitation and LC-MS/MS studies. (B) mFold mRNA secondary structure prediction of the LUC-MS2-4000 3'UTR. The two forming MS2 hairpin structures in silico are indicated by arrows, and the two MS2 binding sites (ACATGAGGATCACCCATGT) are indicated in red. (C) Schematic representation of the LUC-MS2-4000 3'UTR constructs generated and used in this study. The full-length LinJ.36.4000 3'UTR or truncated 3'UTR lacking either SIDER2 ( $\triangle$ SIDER2) or the second hallmark signature sequence $(79-\mathrm{nt})$ of SIDER2 retroposons $(\triangle \mathrm{SII})$ were cloned downstream from the $L U C$ reporter gene. $(D)$ Northern blot hybridization of total RNA from parasites expressing chimeric LUC transcripts regulated by the LinJ36.4000 $3^{\prime}$ UTR or the truncated $3^{\prime}$ UTR. Blots were hybridized with a LUC-specific probe, and the a-tubulin and NEO probes were used as loading controls. Normalized LUC mRNA levels relative to the full-length LUC-4000 $3^{\prime} \mathrm{UTR}$ (control) are shown below the blot. Hybridization intensity signals were quantified using the ImageQuant 5.2 software, and LUC mRNA values were normalized to the a-tubulin and NEO mRNAs. Shown here is one representative experiment out of two independent experiments yielding similar results. (E) Western blot analysis on total lysates from cotransfectants and the PTP-tMCP-HA single transfectant using anti-HA and anti-MCP antibodies to detect the MCP protein. The anti- $\alpha$-tub antibody was used as loading control.

of an effective inducible protein expression system in $L$. infantum, we decided to express MCP episomally to obtain higher levels of expression and consequently sufficient binding to the MS2 SL RNA. Therefore, we generated a tandem MCP construct (tMCP) as MCP binds the hairpin as preformed dimers, thus recruiting two copies of the fused RBP of interest to the tethering site. Bound coat protein dimers interact cooperatively with one another when tandem arrays of hairpins are present (Johansson et al. 1997). The use of tandem MCP has already been shown in mRNA localization studies to improve the signal when fused to GFP (Wu et al. 2012). Western blot using an anti-HA or an anti-MCP antibody demonstrated a suitable expression of the tMCP protein in our transfectants (Fig. 1E), favoring the coat protein-ligand binding in vivo.

\section{Identification of RNA-binding proteins interacting with a SIDER2 reporter RNA using the MS2 coat protein tethering system}

The MS2 coat protein tethering system is a robust in vivo approach to study the functional properties of RBPs by attracting them to any RNA of interest (Keryer-Bibens et al. 2008). To identify RBPs bound to the SIDER2-harboring $3^{\prime}$ UTR of the LinJ.36.4000 transcript, we carried out coimmunoprecipitation (co-IP) studies against the MCP protein combined 
with LC/MS-MS analysis. For these studies, we used L. infantum parasites coexpressing the PTP-tMCP-HA protein with either the LUC-MS2-4000 $3^{\prime}$ UTR (harbors the full-length SIDER2-containing $3^{\prime}$ UTR of LinJ.36.4000 transcript with two MS2 hairpins placed downstream from the LUC reporter gene) or the MS2-LUC-4000 3'UTR (the two MS2 binding sites were placed upstream of the LUC reporter gene) (Fig. $1 \mathrm{~A}, \mathrm{C})$. Placing the MS2 binding sites both upstream and downstream, the $L U C$ reporter permits us to eliminate the possibility of occupational effect on SIDER2-interacting proteins imposed by MCP when it binds to MS2 RNA. UVcrosslinking followed by co-IP experiments against the PTP-tMCP-HA protein using an anti-HA antibody coupled to magnetic beads and mass spectrometry analysis revealed a number of candidate proteins, tethered to SIDER2 RNA (Table 1). The presence of PTP-tMCP-HA protein prior and after co-IP studies was verified by Western blotting (Supplemental Fig. S1). Experiments were done with both L. infantum promastigotes and axenic amastigotes, but only the results with promastigotes are shown here. A control with a non-SIDER2 3'UTR (LinJ.39.3990; LUC-MS2-3990 $3^{\prime}$ UTR) was also used to assess binding specificity (not shown). Only candidate proteins tethered to the LUCMS2-4000 3'UTR mRNA but not to LUC-MS2 or LUCMS2-3990 3'UTR (e.g., two negative controls) were considered for further analysis. These include the XRN $5^{\prime}-3^{\prime}$ exoribonuclease, the deadenylase complex CCR4-NOT1 and NOT5 proteins, an ATP-dependent RNA helicase (Hel 3150), a lupus La protein homolog, the Pumilio-family member PUF6, an RNA-binding protein (RBP-0610), and one hypothetical protein (LinJ.29.2040) with no predicted RBP domain(s) (Table 1). NOT1 was excluded from our study as we failed to amplify the corresponding ORF ( $\sim 7 \mathrm{~kb})$ for cloning purposes. Similarly, NOT5 was excluded from fur- ther investigation as we were unable to detect the fusion protein by Western blotting (see Supplemental Fig. S2) and the transfected cells experienced some growth problems.

\section{The Pumilio-domain protein PUF6 causes the highest mRNA destabilizing effect among the candidate SIDER2-interacting proteins once tethered to a SIDER2-harboring reporter RNA}

To assess the role candidate SIDER2-interacting proteins may play on LUC-SIDER2 transcript stability, we fused mostly at the $\mathrm{C}$ terminus, each of these proteins with the tMCP-HA protein and coexpressed them into L. infantum LUC-MS2$40003^{\prime}$ UTR or LUC-MS2-4000 $\Delta$ SIDER2 recombinant strains (Fig. 2A) and proceeded with tethering assays on stably cotransfected cell lines. The expression of the different tMCP-fused candidate proteins was verified by Western blot analysis (Supplemental Fig. S2). No significant variation in the levels of tethered protein expression was observed between LUC-MS2-4000 3'UTR and LUC-MS2-4000 SIDER2 expressing parasites (Supplemental Fig. S2C). LUC-MS24000 plasmid copy-number variation among the different cotransfectants was determined by Southern blot hybridization (Supplemental Fig. S3). The use of episomal vectors was our best possible choice at the time as it was technically challenging to delete the entire SIDER2 sequence or the 79-nt signature II from a given $3^{\prime} \mathrm{UTR}$ within the genomic locus by homologous recombination. Steady-state levels of LUC mRNA in the different transfectants coexpressing the candidate proteins tethered to the LUC-MS2-4000 SIDER2-bearing reporter RNA were detected by Northern blot hybridization and normalized to the $18 \mathrm{~S}$ rRNA signal (RNA loading variation) as well as to the LUC-MS2-4000 or LUC-MS2-4000 $\Delta$ SIDER2 plasmid copy number (slight

TABLE 1. Candidate proteins bound to the SIDER2-containing $3^{\prime} U T R$ of $L$. infantum LinJ.36.4000 transcript as identified using the MS2 coat protein tethering approach

\begin{tabular}{|c|c|c|c|c|}
\hline \multirow[b]{2}{*}{ Identified proteins } & \multirow[b]{2}{*}{ Accession no. } & \multicolumn{3}{|c|}{ Peptide no. } \\
\hline & & MS2-LUC-4000 & LUC-MS2-4000 & PTP-tMCP-HA \\
\hline MS2 coat protein (MCP) & & $3-4$ & $2-4$ & $2-4$ \\
\hline NOT5 protein & LinJ.25.1920 & $3-5$ & $3-5$ & 0 \\
\hline CCR4-NOT1 transcription complex subunit 1 & LinJ.21.0880 & $2-8$ & $5-8$ & 0 \\
\hline XRN $5^{\prime}-3^{\prime}$ exonuclease, putative & LinJ.16.0400 & $2-4$ & $2-4$ & 0 \\
\hline ATP-dependent RNA helicase, putative & LinJ.35.3150 & $2-4$ & $2-4$ & 0 \\
\hline RNA-binding protein, putative & LinJ.17.0610 & $2-4$ & $2-3$ & 0 \\
\hline Pumilio protein 6 (PUF6), putative & LinJ.33.1210 & $2-3$ & $2-4$ & 0 \\
\hline Lupus La protein homolog, putative & LinJ.21.0600 & $2-4$ & $2-4$ & 0 \\
\hline Hypothetical protein, unknown function & LinJ.29.2040 & $2-3$ & $2-3$ & 0 \\
\hline Hypothetical protein, conserved & LinJ.12.0400 & $2-2$ & $2-2$ & 0 \\
\hline
\end{tabular}

L. infantum parasites cotransfected with LUC-MS2-4000 or MS2-LUC-4000 and the PTP-tMCP-HA protein were subjected to UV-crosslinking, coimmunoprecipitation, and LC-MS/MS analysis. Results shown here are representative of three independent experiments with $1 \%$ false discovery rate (FDR). Only selected proteins bound to the SIDER2-harboring $3^{\prime} U T R$ of the $L$. infantum Linj.36.4000 transcript but not identified in the PTP-tMCP-HA transfectant (control) are shown here. Proteins identified with $>2$ peptides and a probability of $>95.0 \%$ were considered. The number of peptides shown represents the minimum and maximum values found in the triplicate experiments. 
A

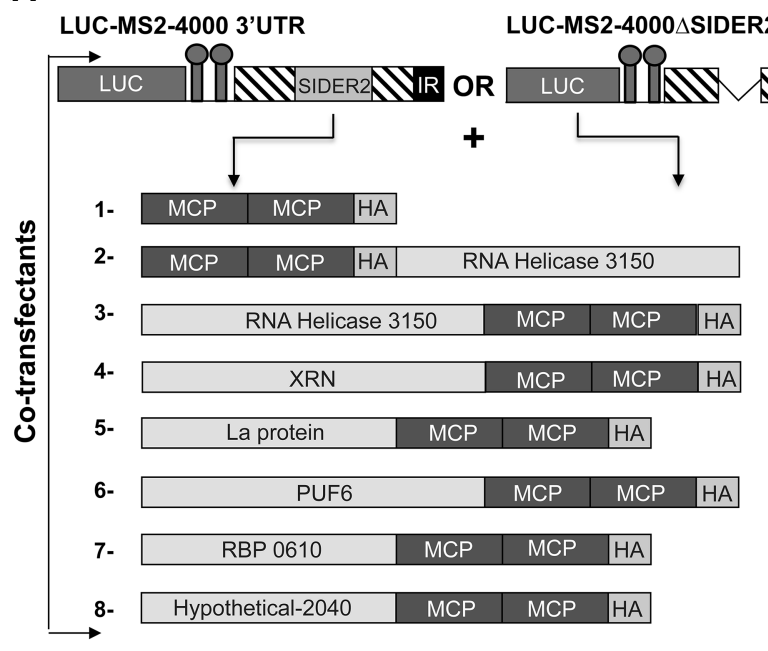

B

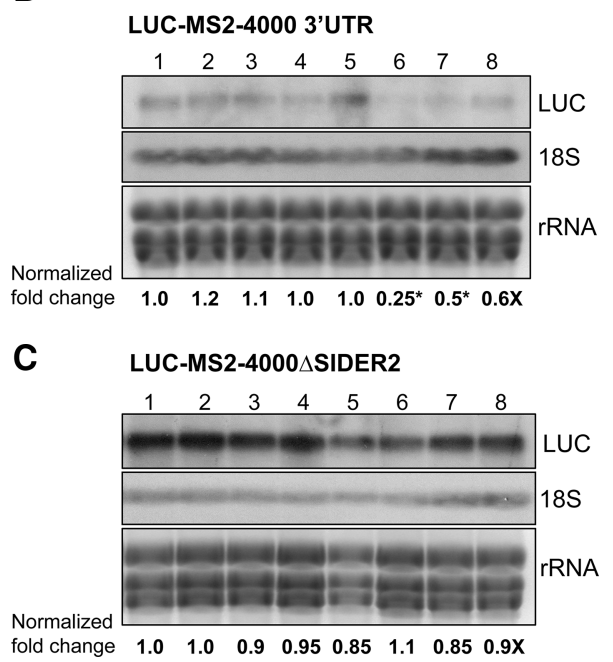

FIGURE 2. Candidate proteins tethered to a SIDER2-containing $3^{\prime}$ UTR or to a truncated $3^{\prime}$ UTR lacking SIDER2. (A) Schematic overview of the constructs made to tether candidate proteins fused with the tandem tMCP-HA to LUC-MS2-4000 3'UTR or LUC-MS2-4000 2 SIDER2 RNAs. Northern blot hybridization of total RNA isolated from L. infantum parasites coexpressing the candidate proteins in $(A)$ and the LUC reporter chimeric construct with either the full-length $3^{\prime}$ UTR of LinJ36.4000 (B) or a truncated 3'UTR lacking SIDER2 (C). The blot was hybridized with a $L U C$ specific probe to assess mRNA levels upon tethering of the different candidate proteins. The $18 \mathrm{~S}$ rRNA probe and ethidium bromide staining were used as controls for RNA loading. Hybridization intensity signals were quantified by the ImageQuant 5.2 software and $L U C$ transcript abundance was normalized to the $18 \mathrm{~S}$ rRNA hybridization signal and also to the LUC-plasmid copy number in each tMCP-HA transfectant (see Supplemental Fig. S3). Normalized values indicated below the blot are relative to the control strain coexpressing the LUC-MS2-4000 3'UTR or the LUC-MS2$4000 \triangle$ SIDER2 and tMCP-HA (lane 1). Shown here is one representative experiment out of three independent experiments yielding similar results. An asterisk indicates the most important differences in $L U C$ mRNA levels.

variations were observed between different transfectants; see Supplemental Figs. S3, S4). Normalization of the Northern blot data indicated that among the six candidate proteins investigated here, tethering of PUF6 to the LUC-MS2-4000 mRNA led to the highest effect on RNA fate, with a fourfold decrease in LUC mRNA levels (Fig. 2B). No destabilizing effect was observed upon tethering of PUF6 to the LUCMS2-4000 $\triangle$ SIDER2 mRNA (Fig. 2C), indicating that PUF6 has to bind sequences within SIDER2. Two other proteins, RBP-0610 and the hypothetical protein 2040, once tethered to the LUC-MS2-4000 mRNA, resulted in a 2.0 -fold and 1.66-fold decrease in $L U C$ mRNA levels, respectively (Fig. 2B). In this study, however, we focused on PUF6 protein, primarily due to its highest destabilizing effect on the $L U C$ SIDER2 RNA.

\section{Tethering PUF6 protein to a SIDER2-harboring reporter RNA enhances degradation through binding to SIDER2 regulatory sequences}

To determine whether PUF6 binds to the second tandem 79nt SIDER2 signature sequence (SII), shown to be the target of endonucleolytic cleavage (Müller et al. 2010b; Azizi et al. 2017b), we generated another recombinant parasite cell line coexpressing the PUF6-tMCP protein together with the LUC-MS2-4000 $\Delta$ SII mRNA. This enables us to compare the results of PUF6 tethering to the LUC-MS2-4000 $\Delta$ SII with PUF6 tethering to LUC-MS2-4000 3'UTR RNAs by
Northern blot hybridization. Cotransfectants with the tMCP-HA were also used as controls for comparative studies. LUC mRNA fold-differences were determined following normalization of the hybridization $L U C$ signal intensities to the a-tubulin signal (RNA loading control) as well as to the plasmid copy number (Supplemental Figs. S3, S5). Normalized LUC mRNA values indicated that PUF6 confers a fourfold decrease in LUC-MS2-4000 3'UTR mRNA levels when compared to the control tMCP-HA protein tethered to the same RNA (Fig. 3, left panel). However, PUF6 did not alter LUC mRNA levels when tethered to a reporter transcript lacking SIDER2 (LUC-MS2-4000 $\Delta$ SIDER2) (Fig. 3, middle panel), as also shown in Figure $2 \mathrm{C}$. Interestingly, we found that once tethered to the LUC-MS2-4000 $\Delta$ SII RNA, PUF6 does decrease $L U C$ mRNA levels by 2.5 -fold (Fig. $3 \mathrm{~A}$, right panel) as compared to fourfold when tethered to the full-length SIDER2-harboring 3'UTR (Fig. 3, left panel). Altogether, these data suggest that PUF6 binds sequences (or RNA structure) within SIDER2, including signature II, but not exclusively, to accelerate mRNA decay.

We showed that artificial binding of PUF6 to SIDER2 sequences accelerates mRNA decay (Figs. 2, 3). Further, we investigated if decreased mRNA levels upon PUF6 tethering are due to an increased destabilization. To address this question, we measured LUC mRNA half-lives upon tethering of PUF6 to the reporter RNA and compare them with the MCP tethering control. LUC mRNA stability was assessed by Northern blotting on total RNA treated prior with actinomycin D 


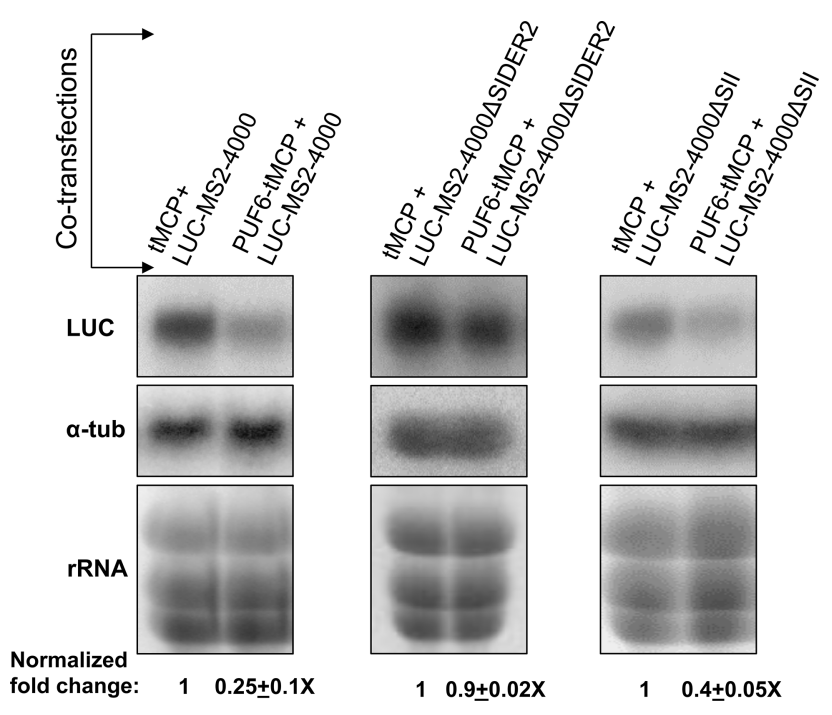

FIGURE 3. Tethering of the Pumilio 6 protein (PUF6) to a SIDER2harboring $3^{\prime}$ UTR enhances mRNA decay rates. Northern blot analysis of total RNA isolated from L. infantum coexpressing the tMCP-HA control protein or the PUF6-tMCP-HA with LUC-MS2-4000 3'UTR (left panel), LUC-MS2-4000 $\triangle$ SIDER2 (middle panel), or LUC-MS2$4000 \Delta$ SII (lacking only the signature II sequence) (right panel). The blots were hybridized with a $L U C$-specific probe to evaluate $L U C$ mRNA decay rates upon tethering of the control protein tMCP-HA or the PUF6-tMCP-HA. The $\alpha$-tubulin probe was used as loading control. Fold changes of $L U C$ mRNA levels upon PUF6 tethering relative to the tMCP-HA control shown below the blots were normalized with $a$-tub hybridization signals for RNA loading as well as plasmid copy numbers (see Supplemental Figs. S3-S5 for copy-number variations between plasmids in the different transfectants). Shown here is one representative experiment out of two independent experiments yielding similar results.

(ActD) (Fig. 4). A time course ActD treatment showed that tethering of PUF6 to the LUC-MS2-4000 3'UTR decreased mRNA stability by twofold $\left(t_{1 / 2}: 26 \mathrm{~min}\right)$ in comparison to the control experiment using the tMCP protein $\left(t_{1 / 2}: 52\right.$ $\min$ ) (Fig. 4A,B). It is worth noticing that although tethering of PUF6 to the LUC-MS2-4000 3'UTR promotes a fourfold decrease in mRNA levels (Figs. 2B, 3), only a twofold destabilization was observed (Fig. 4). This may be due to the constitutive and uncontrollable tethering of PUF6 to SIDER2 mRNA. To determine half-lives of SIDER2-harboring transcripts, as shown on the $y$-axis of the charts (Fig. 4, lower panels), we decided not to use a logarithmic scale for the percentage of remaining mRNA as being used commonly because of our previous observations that SIDER2-mediated mRNA decay occurs in a biphasic manner: a rapid endonucleolytic cleavage followed by further degradation of the cleavage products via the action of exoribonucleases and deadenylases (Müller et al. 2010b).

To assess whether the PUF6-mediated destabilizing effect involves the SIDER2 element, we carried out ActD treatment on parasites coexpressing the PUF6-tMCP protein together with the LUC-MS2-4000 $\Delta$ SIDER2 plasmid. As depicted in Figure 5, tethering PUF6 to a $3^{\prime}$ UTR lacking SIDER2 did not alter the LUC mRNA half-life $\left(t_{1 / 2}: 92.6 \mathrm{~min}\right)$ as compared to the MCP tethering ( $t_{1 / 2}: 107 \mathrm{~min}$ ) (Fig. 5A,B), hence corroborating the steady-state levels of LUC-MS2$4000 \triangle$ SIDER2 mRNA (Fig. 2C). The fact that tethering of PUF6 to a SIDER2-containing reporter RNA enhances degradation supports that PUF6, through binding to SIDER2 sequences, contributes to SIDER2-mediated decay.

\section{Genetic inactivation of PUF6 results in increased stabilization of SIDER2-containing endogenous transcripts}

To investigate further the role PUF6 plays in SIDER2-mediated mRNA decay, we generated a L. infantum PUF6 null mutant strain. Both PUF6 alleles were successfully replaced sequentially with the hygromycin $(H Y G)$ and neomycin phosphotransferase (NEO) resistance genes, as confirmed by Southern blot hybridization (Fig. 6A), indicating that the PUF6 gene is not essential for Leishmania promastigote growth. Next, we evaluated the effect of PUF6 gene inactivation on SIDER2-harboring LinJ.36.4000 and LinJ.08.1220 transcript expression levels by Northern blot hybridization. Both transcripts have been studied extensively in our laboratory (Bringaud et al. 2007; Müller et al. 2010a,b). Interestingly, we observed an increased accumulation of both 4000 and 1220 transcripts by 1.8 -fold and 2.6-fold, respectively, in the PUF6 ${ }^{-1-}$ knockout (Fig. 6B), which further confirms that PUF6 plays a role in SIDER2-mediated decay.

To examine changes in 4000 and 1220 mRNA stability in the absence of PUF6, we treated L. infantum wild-type and $\mathrm{PUF}^{-1-}$ strains with ActD at indicated time points, and total RNA extracted from these strains was subjected to Northern blot hybridization. Interestingly, half-lives of 4000 and 1220 transcripts were increased by at least twofold in the absence of PUF6 (from $18 \mathrm{~min}$ in WT to $32 \mathrm{~min}$ in $\mathrm{PUF6}^{-1-}$ for 4000 , and from $15 \mathrm{~min}$ in WT to $34.5 \mathrm{~min}$ in $\mathrm{PUF6}^{-1-}$ for 1220) (Fig. 6C). These results corroborate our findings that PUF6 contributes to SIDER2-mediated mRNA decay. In another attempt to validate the effect of PUF6 depletion on the stability of 4000 and 1220 transcripts, we treated parasites with cycloheximide ( $\mathrm{CHX})$ to inhibit translation elongation and then analyzed total RNA extracted from those cells at various time points post-treatment by Northern blotting. The aim of this experiment was to compare accumulation rates of SIDER2-harboring transcripts between wild-type and PUF6 ${ }^{-1-}$ parasites under conditions of global translation inhibition where de novo-synthesis of mRNA decay factors, including PUF6, could be affected. Interestingly, accumulation of both 4000 and 1220 transcripts increased by approximately 2.5 - to 3.5-fold on average, after $4-6 \mathrm{~h}$ of CHX treatment in $\mathrm{PUF}^{-/-}$parasites compared to the wild-type strain (Supplemental Fig. S6), suggesting that PUF6 is required for optimal decay of SIDER2-bearing transcripts. 
A
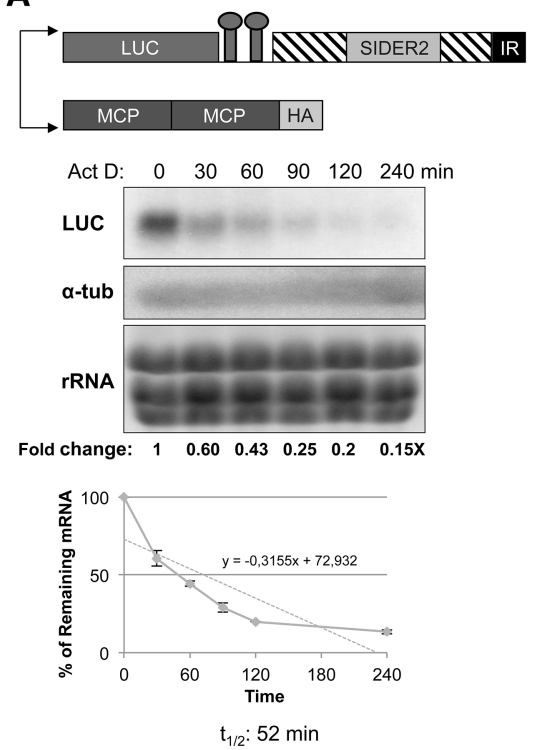

B
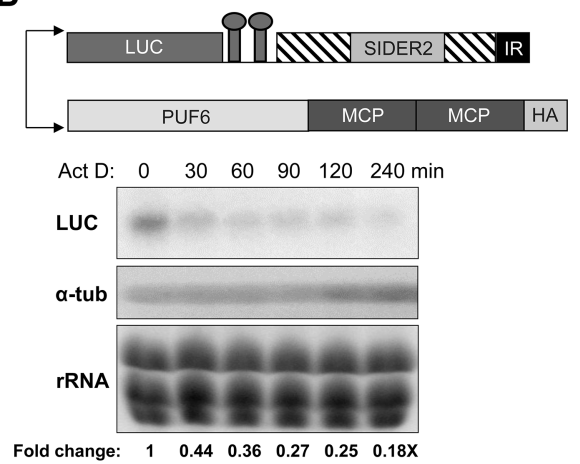

Fold change: $\begin{array}{llllll}1 & 0.44 & 0.36 & 0.27 & 0.25 & 0.18 \mathrm{X}\end{array}$

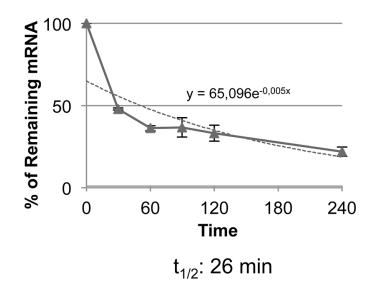

FIGURE 4. Tethering of PUF6 protein to a SIDER2-harboring 3'UTR leads to an increased mRNA destabilization. (A) Schematic drawing of the vectors coexpressed in L. infantum and used to tether tMCP-HA to the LUC-MS2-4000 3'UTR (top panel). Northern blot analysis of actinomycin D (ActD)-treated parasites to assess changes in $L U C$ transcript stability upon tMCP tethering (control). ActD was added at the concentration of $10 \mu \mathrm{g} / \mathrm{mL}$, parasites were harvested at indicated time points, and total RNA was isolated for Northern blotting (middle panel). Blots were hybridized with LUC or a-tubulin (loading control) probes. The numbers indicated below the blots represent the fold difference in LUC mRNA expression levels relatively to the ActD T0. These values were used to calculate the half-life of the LUC mRNA upon tethering of the tMCP control (lower panel). Due to the biphasic nature of SIDER2 mRNA degradation (Müller et al. 2010b), values corresponding to each time point were plotted in linear values of percentage of the remaining mRNA. $(B)$ Schematic of the constructs used to tether PUF6 to the LUC-MS2-4000 3'UTR (top). Northern blot analysis of ActD-treated parasites as in A hybridized with LUC or $\alpha$-tubulin probes to determine the half-life of the LUC transcript upon PUF6 tethering (middle). Half-lives $\left(t_{1 / 2}\right)$ were estimated when the percentage of remaining mRNA after time zero (T0) reached 50\% mRNA abundance (lower panel). Standard deviations are from three independent experiments.

\section{DISCUSSION}

"Tethering" approaches have been used successfully to isolate proteins that activate mRNA turnover in human cells (Clement and Lykke-Andersen 2008; Park et al. 2013; Yokoshi et al. 2014) but also in parasites (Erben et al. 2014). Here, we report for the first time in trypanosomatid protozoa, the use of the MS2 coat protein tethering system to capture RNA-binding proteins (RBPs) regulating mRNA decay. We have optimized this system for use in Leishmania, which combined with immunoprecipitation and mass spectrometry analysis led us to the identification of trans-acting factors bound specifically to SIDER2 retroposon elements and regulating SIDER2-mediated mRNA decay. Among the several candidate RNA-binding proteins with known functions in mRNA decay that were tethered to a SIDER2 reporter RNA, the Pumilio-domain protein PUF6 was shown to play a role in the SIDER2-mediated mRNA decay process.

We provide several lines of evidence supporting a functional role of PUF6 in SIDER2-mediated mRNA decay. We show that tethering of PUF6 to a SIDER2-harboring $3^{\prime} U T R$ exacerbates RNA degradation but has no effect on an RNA lacking SIDER2. Accordingly, genetic inactivation of PUF6 leads to an increased accumulation and higher stability of Leishmania transcripts harboring a SIDER2 element in their $3^{\prime}$ UTR. The effect of PUF6 on SIDER2-containing mRNA destabilization is the result of specific binding to sequences within SIDER2 that include, but not exclusively, the second conserved 79nt signature sequence (signature II) of SIDER2 retroposons, which is the target of endonucleolytic cleavage (Müller et al. 2010b; Azizi et al. 2017b). Indeed, tethering of PUF6 to a SIDER2 element lacking signature II decreases RNA stability albeit to a lesser extent than tethering to the full-length SIDER2 RNA. We have shown recently that SIDER2-mediated mRNA decay is coupled to translation (Azizi et al. 2017a), and our findings here that inhibition of global protein synthesis by cycloheximide increases the accumulation of SIDER2-harboring Leishmania transcripts by at least twoto threefold in the PUF6 ${ }^{-1-}$ knockout in comparison to the wild-type strain, suggest that PUF6 contributes to the decay mechanism while associated with SIDER2-bearing mRNAs on translating ribosomes.

The Pumilio proteins are well-known RNA-binding proteins in most eukaryotic lineages. This family has expanded in trypanosomatids with 10 members in Leishmania (Luu et al. 2006), whereas only five members were found in the yeast Saccharomyces cerevisiae and two in humans. In many organisms such as $S$. cerevisiae, Drosophila melanogaster, C. elegans, and H. sapiens, several Pumilio repeats within PUF proteins share the UGUR ( $R$ represents a purine) recognition sequence flanked by downstream or upstream sequences often unique to each PUF protein (Wickens et al. 2002; Miller et al. 2008; Ulbricht and Olivas 2008). In all these cases, PUF proteins comprise eight sequence repeats (called PUM repeats) and flanking $\mathrm{N}$ - and C-terminal regions (Zhang et al. 1997), out of which repeats 5-8 recognize the UGUR tetranucleotide motif. However, similarly to the yeast Puflp and Puf2p homologs, the Leishmania PUF6 is predicted to encompass 6 PUM repeats (Supplemental Fig. S7), and this suggests that binding via a consensus sequence may be dispensable (Ulbricht and Olivas 2008). At the molecular level, PUF proteins promote translational repression and/or mRNA degradation first by interacting specifically with cis-elements in the $3^{\prime}$ UTR of their target mRNAs and through complex interactions with 
A
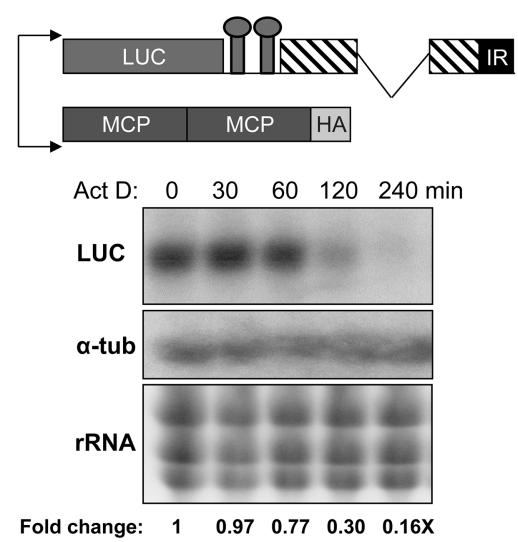

Fold change: $\quad \begin{array}{lllll}1 & 0.97 & 0.77 & 0.30 & 0.16 \mathrm{X}\end{array}$

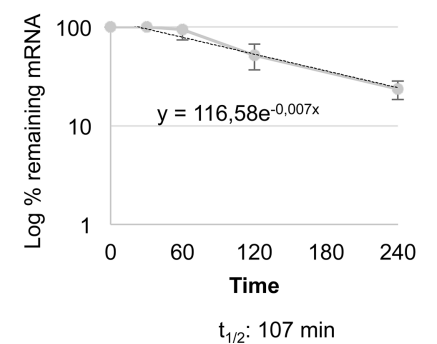

FIGURE 5. Tethering of PUF6 protein to a truncated $3^{\prime}$ UTR lacking SIDER2 does not alter RNA stability. (A) Schematic drawing of the vectors coexpressed in L. infantum and used as a control (top panel). Northern blot analysis of ActD-treated parasites hybridized with LUC or a-tubulin probes (middle). The graph in the lower panel shows the half-life of the LUC transcript upon tethering of the control tMCP protein. $(B)$ Schematic drawing of the constructs used to tether PUF6 to the LUC-4000 $\triangle$ SIDER2 (top panel). Northern blot analysis of ActD-treated parasites as in $A$ hybridized with LUC or a-tubulin probes to determine the half-life of the LUC transcript upon PUF6 tethering (middle panel). The numbers indicated below the blots represent the fold difference in expression ratios compared to the T0 value and were used in the half-life charts. The graph shows the half-life of the LUC transcript upon PUF6 tethering (lower panel). In the absence of the SIDER2 element, mRNA decay follows a conventional pattern. The $y$-axis referring to the percentage of remaining mRNA was set to log scale. Standard deviations are from three independent experiments.

protein cofactors and the translation and degradation regulatory components (Wang et al. 2002; Cheong and Hall 2006; Lublin and Evans 2007; Ulbricht and Olivas 2008; Chritton and Wickens 2010; Cooke et al. 2011; Miller and Olivas 2011; Quenault et al. 2011).

There is increasing evidence in the literature that members of the PUF family play an important role in mRNA decay. Indeed, members of the PUF family bind to $3^{\prime}$ UTRs of various eukaryotic mRNAs and enhance turnover, acting combinatorially with the CCR4-NOT deadenylase complex (Quenault et al. 2011). In humans, PUF proteins, PUM1 and PUM2, recruit the CCR4-NOT complex to stimulate mRNA decay and repress translation (Van Etten et al. 2012). In S. cerevisiae, recruitment of CCR4p, the catalytic subunit of the CCR4-POP2-NOT deadenylase complex, by PUF3p, PUF4p or PUF5p, results in mRNA deadenylation (Goldstrohm et al. 2006, 2007; Hook et al. 2007; Lee et al. 2010). A similar mechanism has been reported in Drosophila, C. elegans, and humans, where recruitment of the deadenylase complex POP2p subunit by PUF proteins stimulates deadenylation of target mRNAs (Goldstrohm et al. 2006; Kadyrova et al. 2007; Suh et al. 2009). Here, MS2 protein tethering to a SIDER2-containing reporter RNA led also to the identification of CCR4-NOT1 and NOT5 deadenylases. However, our previous data support a model for SIDER2-mediated decay, which is deadenylation-independent (Müller et al. 2010b). Therefore, these deadenylases may be recruited to a SIDER2 reporter RNA through their association with PUF6, which specifically binds sequences within SIDER2. In yeast, it has been shown that PUF4p and PUF5p bind to the $H O$ mRNA $3^{\prime} \mathrm{UTR}$, repressing translation, triggering deadenylation and thus mRNA decay, possibly through their association with the decapping activator DCP1p and the DHH1p helicase (Goldstrohm et al. 2006, 2007; Hook et al. 2007). A similar decay mechanism has been proposed in the related trypanosomatid, Trypanosoma cruzi, where PUF6 binds to a subset of mRNAs and its overexpression results in the down-regulation of target transcripts in epimastigotes, possibly through its association with the TcDHH1 helicase (Dallagiovanna et al. 2008). In Leishmania, however, overexpression of PUF6 did not affect steadystate levels of SIDER2-containing transcripts (Supplemental Fig. S8), suggesting that for PUF6 to enhance destabilization of SIDER2 transcripts it has to be artificially tethered to these RNAs. This could imply that PUF6 binds with higher specificity to SIDER2 target mRNAs. Although coimmunoprecipitation experiments against a PUF6-HA protein were not very optimal due to proteolytic degradation of PUF6 under nondenaturing conditions, mass spectrometry studies identified DHH1 as one of the PUF6-interacting proteins together with another decay protein, the Dis3-like ribonuclease, an exoribonuclease associated with the human exosome (Staals et al. 2010) (data not shown). Additional preliminary experiments using the BioID method (Roux et al. 2012) as an alternative approach to coimmunoprecipitation, have also led to the identification of the Dis3-like ribonuclease as a PUF6-interacting factor (data not shown). Thus, PUF6 might possibly enhance decay of SIDER2-containing transcripts by facilitating the recruitment of exoribonucleases. Moreover, the fact that PUF6 accelerates mRNA decay only once tethered to SIDER2 sequences, including the second conserved 79-nt signature of SIDER2 retroposons shown previously to be central to endonucleolytic cleavage and degradation (Müller et al. 2010b; 
A

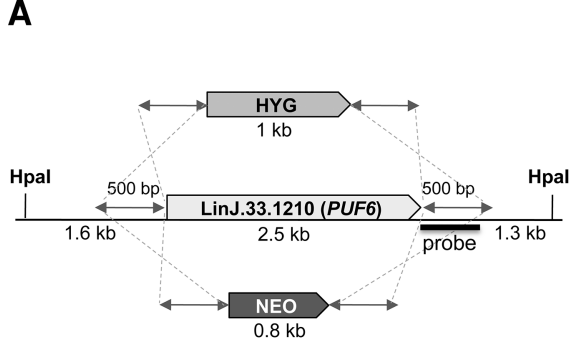

C

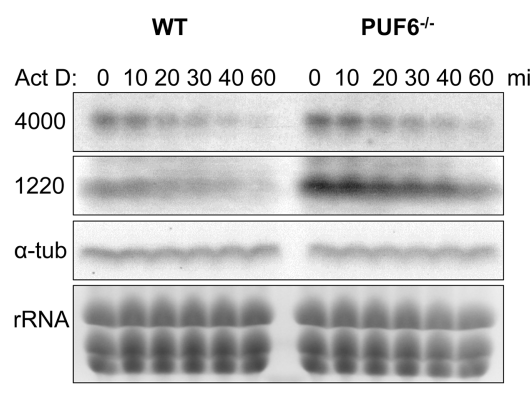

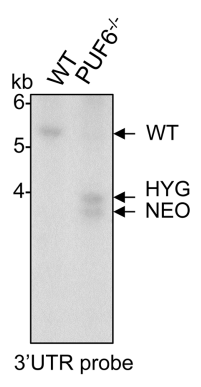

B
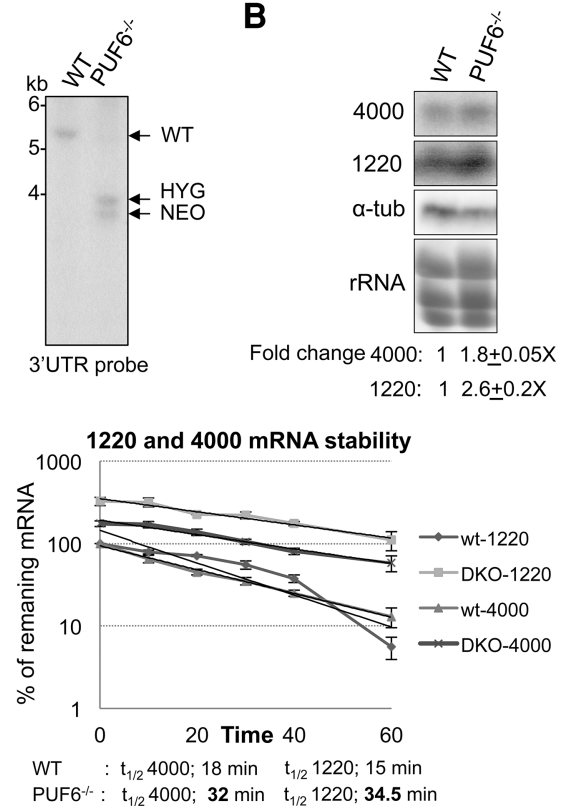

FIGURE 6. Genetic inactivation of PUF6 leads to increased accumulation and stability of SIDER2-containing endogenous transcripts. (A) Schematic drawing of PUF6 gene replacement in L. infantum by the neomycin phosphotransferase (NEO) and hygromycin B (HYG) expression targeting cassettes through homologous recombination (left panel). Southern blot hybridization of L. infantum wild-type (WT) and PUF6 ${ }^{-/-}$knockout genomic DNA digested with HpaI. The blot was hybridized with a 500-bp probe at the $3^{\prime}$ flanking sequence of the PUF6 gene that detects a 5.4-kb fragment in the WT strain and 3.9- and 3.7-kb fragments in the PUF6 ${ }^{-1-}$ knockout corresponding to the HYG and NEO gene replacements. $(B)$ Northern blotting of total RNA isolated from $L$. infantum WT and PUF6 ${ }^{-9-}$. The blots were hybridized with specific probes recognizing the L. infantum SIDER2-bearing transcripts, LinJ.36.4000 (4000) and LinJ.08.1220 (1220). The $\alpha$ tubulin probe was used as RNA loading control. Ethidium bromide staining was also included to visualize rRNA as an additional loading control. Fold changes of 4000 and 1220 endogenous transcripts in the PUF6 ${ }^{-1-}$ knockout relative to the WT are shown here below the blots and were calculated after normalization against the loading controls. Standard deviations are the result of three independent experiments. (C) Stability of SIDER2-harboring LinJ.36.4000 and LinJ.08.1220 transcripts was compared between the WT and $\mathrm{PUF}^{-1-}$ strains following a time course treatment with the RNA Pol II transcription inhibitor ActD. Parasites were collected at indicated time points, and total RNA was extracted and subjected to Northern blotting. Blots were hybridized with specific probes against LinJ.36.4000 and LinJ.08.1220 as well as the $\alpha$-tubulin gene (RNA loading control) (left panel). Graphical display of the half-lives of 4000 and 1220 transcripts in WT and PUF6 $^{-1-}$ (right panel). Half-lives $\left(t_{1 / 2}\right)$ were estimated when the percentage of the remaining mRNA after time zero (T0) reached $50 \%$ of mRNA abundance.

Azizi et al. 2017b), supports the possibility that PUF6 facilitates recognition of SIDER2 by the endoribonuclease.

In summary, this study led to the identification of Pumiliodomain protein PUF6 as the first trans-acting factor shown to interact with SIDER2 regulatory sequences and to accelerate mRNA decay. SIDER2-mediated mRNA decay is initiated through endonucleolytic cleavage(s) within the second conserved 79-nt signature sequence at the $5^{\prime}$ end of all SIDER2 retroposons, followed by $5^{\prime}-3^{\prime}$ and $3^{\prime}-5^{\prime}$ degradation of mRNA ends by exoribonucleases (Müller et al. 2010b). Thus, multiple factors are expected to form the SIDER2-specific decay complex. The identification of PUF6 as one of the contributing factors to SIDER2-mediated mRNA decay would permit the isolation of other components of the decay complex and shed more light onto this complex mechanism of regulated mRNA decay in parasitic protozoa.

\section{MATERIALS AND METHODS}

\section{Leishmania culture and transfections}

Leishmania infantum MHOM/MA/67/ ITMAP-263 (Sereno et al. 2001) promastigotes were cultured in SDM-79 medium supplemented with $10 \%$ FCS (Wisent) and $5 \mu \mathrm{g} /$ $\mathrm{mL}$ hemin at $25^{\circ} \mathrm{C}$. On average, $10-20 \mu \mathrm{g}$ plasmid DNA were transfected into Leishmania promastigotes by electroporation as previously described (Papadopoulou et al. 1992). To generate stable transfectant cell lines, parasites were selected with $25 \mu \mathrm{g} / \mathrm{mL}$ G418 (Sigma-Aldrich), $10 \mathrm{mg} / \mathrm{mL}$ zeocin (Life Technologies), or hygromycin B (Sigma-Aldrich) at $1 \mathrm{mg} / \mathrm{mL}$.

\section{Tethering constructs}

The parent plasmid pSP72-YNEOaIR described elsewhere (Wu et al. 2000) was used to generate the LUC-MS2-3'UTR constructs. pSP72-YNEO $\alpha$-LUC-MS2-4000 3'UTR (Y stands for a 92-bp polypyrimidine stretch [Papadopoulou et al. 1994]; $\alpha$, for the intergenic region of the $\alpha$-tubulin gene; NEO for the neomycin phosphotransferase gene; and LUC for the luciferase gene) was constructed by PCR amplification of the LinJ.36.4000 3'UTR (Phusion Taq polymerase, Thermo Scientific) using primers described in Supplemental Table S1 and subsequently cloned downstream from the LUC gene. The two MS2 hairpins (see Fig. 1B) were placed at the beginning of the $40003^{\prime}$ UTR via PCR amplification using the forward primer containing the MS2 sequences. To generate LUC-MS2-4000 $\Delta$ SIDER2, an overlapping fusion PCR approach was used. A similar strategy was used to create LUC-MS2-4000 $\Delta$ SII lacking only the second 79-nt signature sequence in SIDER2. To construct plasmid pSP72aNEOaMS2LUC-4000 3'UTR, the MS2-LUC fragment was PCR-amplified and cloned via BamHI-HindIII sites into vector pSP72aNEOa (Papadopoulou et al. 1994). Next, the $3^{\prime}$ UTR of LinJ.36.4000 was amplified and cloned into HindIII downstream from the $L U C$ gene. To create the MCP-PTP fusion plasmid, the MS2 coat protein (MCP) tagged with a PTP epitope was first amplified from plasmid pLEW100-PTP-MCP (a generous gift from Dr. Schimanski, Bern, Switzerland) and cloned into XbaI-HindIII sites of pSP72aZEO $\alpha$ (Richard et al. 2004). Then, the second MCP-encoding gene was PCR-amplified and cloned in the HindIII site of pSP72 $\alpha$ ZEO $\alpha$ PTP-MCP to obtain pSP72 $\alpha$ ZEO $\alpha$ PTP-tMCP harboring two tandem MCP copies. To generate pSP72aZEOa-tMCP, the tandem MCP from the PTP-tMCP plasmid was amplified and cloned into the XbaI site of pSP72aZEOa. Genes encoding for candidate proteins interacting with SIDER2 identified using the MS2 tethering system (see Table 1) were cloned upstream of the tMCP- 
HA construct. $L U C$ chimeric transcripts and tMCP-fusion genes are all properly $5^{\prime}$-trans-spliced and processed by the Leishmania enriettii a-tubulin intergenic region (aIR). In order to make a PUF6 (LinJ.33.1210) null mutant in L. infantum, two targeting cassettes comprising either the hygromycin (HYG) or the neomycin (NEO) phosphotransferase genes, flanked by 500 bp DNA fragments at $5^{\prime}$ and $3^{\prime}$ regions of the PUF6 gene, were generated by overlapping PCR. The nucleotide sequence of all primers used to make the above constructs is indicated in Supplemental Table S1.

\section{DNA, RNA, and protein manipulations}

DNA extractions were carried out using DNAzol (Life Technologies). Plasmid copy number was estimated by Southern blot hybridization analysis. Approximately $10 \mu \mathrm{g}$ of DNA from each transfectant digested with NdeI was hybridized with a LinJ.36.4000 3'UTR (1 kb) radiolabeled probe. Hybridization intensity signals from plasmid and genomic DNA were measured by a PhosphorImager. A ratio of the signal obtained from the plasmid DNA versus the genomic DNA was used to determine the plasmid copy number in each transfectant cell line. Total RNA from parasites was isolated by TRIzol (Life Technologies) according to manufacturer's instructions and resolved on $1 \%$ agarose formaldehyde gels. Northern blots were carried out following standard procedures (Sambrook and Russell 2001). Radioactive DNA probes corresponding to the LUC ORF or to the LinJ.36.4000 3'UTR were synthesized using Klenow fragment DNA polymerase I (New England Biolabs) in the presence of $\left[\alpha^{-32} \mathrm{P}\right]$ dCTP (PerkinElmer) and random oligonucleotides (NEB) and used in Northern or Southern blots. Western blots were performed from total $L$. infantum lysates equivalent to $2 \times 10^{6}$ parasites in $2 \times$ Laemmli buffer. HA-tagged proteins were detected using a mouse monoclonal anti-HA tag antibody (Abmgood). The MCP was detected using an anti-MCP rabbit polyclonal antibody (EMD Millipore). Loading control was assessed by rehybridizing the same membrane with a mouse antia tubulin antibody (Sigma-Aldrich) or a rabbit anti-NEO antibody (EMD Millipore). Anti-mouse HRP-conjugated, anti-rabbit HRP-conjugated, or anti-goat HRP-conjugated antibodies were used as secondary antibodies. The blots were visualized by chemoluminescence with an ECL+ Western Blotting Detection Kit (GE Healthcare).

\section{mRNA half-lives and protein synthesis inhibition}

To evaluate the stability of SIDER2-harboring mRNAs expressed as part of episomal vectors or from the genomic locus, we treated mid$\log$ phase L. infantum promastigotes with $10 \mu \mathrm{g} / \mathrm{mL}$ of actinomycin $\mathrm{D}$ (ActD; Gibco-Life technologies) and $2.5 \mu \mathrm{g} / \mathrm{mL}$ sinefungin (Abcam) to arrest de novo transcription and pre-mRNA trans-splicing, respectively. Sinefungin was added 5 min prior to ActD (Li et al. 2006; Haile et al. 2008). Total RNA was isolated at desired time points and analyzed by Northern blotting. To inhibit global protein synthesis, mid-log phase promastigotes were incubated with $10 \mu \mathrm{g} /$ $\mathrm{mL}$ cycloheximide (Sigma-Aldrich), and at various time points, parasites were collected, total RNA isolated and analyzed by Northern blot hybridization. Following transfer, membranes were exposed to a Phosphorimager, and signal intensity was measured using the ImageQuant 5.2 software.

\section{Immunoprecipitation and mass spectrometry analysis}

Frozen parasite pellets were immediately resuspended in the lysis buffer comprising $25 \mathrm{mM}$ Tris- $\mathrm{HCl} \mathrm{pH} \mathrm{7.4,} 100 \mathrm{mM} \mathrm{NaCl}, 1.5$ $\mathrm{mM} \mathrm{MgCl} 2,1 \mathrm{mM}$ EDTA, $0.5 \% \mathrm{NP} 40,5 \%$ glycerol, and $1 \mathrm{mM}$ PMSF supplemented with protease inhibitors (Roche). Lysis was completed by 20-30 strokes of a Dounce homogenizer while on ice. Cell debris and insoluble material were separated by $30 \mathrm{~min}$ centrifugation at $10,000 \mathrm{~g}$ at $4^{\circ} \mathrm{C}$. Supernatants were then incubated with Protein $\mathrm{G}$ magnetic beads (Thermo Scientific) for $30 \mathrm{~min}$ at $4^{\circ} \mathrm{C}$ in order to reduce nonspecific binding and to eliminate protein binding to the beads. Clear supernatants were further incubated with Protein $\mathrm{G}$ anti-HA magnetic beads at $4^{\circ} \mathrm{C}$ for $4 \mathrm{~h}$ on a gentle rotator. Beads were then washed by TBS- $0.05 \%$ Tween (SigmaAldrich) three times (30 sec each) by gentle agitation and subjected to LC-MS/MS analysis as previously described (Padmanabhan et al. 2016). Immunoprecipitation experiments were done on cotransfected parasites as above except that prior to freezing the parasites in liquid nitrogen, they were exposed to $400 \mathrm{~mJ} / \mathrm{cm}^{2} \mathrm{UV}$ irradiation on a Stratalinker 2400 UV crosslinker in PBS medium and then immediately harvested and snap-frozen.

\section{SUPPLEMENTAL MATERIAL}

Supplemental material is available for this article.

\section{ACKNOWLEDGMENTS}

H.A. was a recipient of a fellowship from the Canadian Institutes of Health Research (CIHR) Strategic Training Program STP-53924 and the Centre for Host-Parasite Interactions (CHPI) funded by the Fonds de Recherche du Québec-Nature et Technologies. This work was supported by the Canadian Institutes of Health Research Grant MOP-12182 awarded to B.P.

Received July 12, 2017; accepted September 5, 2017.

\section{REFERENCES}

Archer SK, Luu VD, de Queiroz RA, Brems S, Clayton C. 2009. Trypanosoma brucei PUF9 regulates mRNAs for proteins involved in replicative processes over the cell cycle. PLoS Pathog 5: e1000565.

Azizi H, Müller-McNicoll M, Papadopoulou B. 2017a. SIDER2 retroposon-mediated mRNA decay in Leishmania is coupled to translation. Int J Parasitol 47: 305-310.

Azizi H, Romão TP, Charret SK, Padmanabhan KP, de Melo Neto OP, Müller-McNicoll M, Papadopoulou B. 2017b. RNA secondary structure and nucleotide composition within the conserved hallmark sequence of Leishmania SIDER2 retroposons are essential for endonucleolytic cleavage and mRNA degradation. PLos One 12: e0180678.

Bates PA, Rogers ME. 2004. New insights into the developmental biology and transmission mechanisms of Leishmania. Curr Mol Med 4: 601-609.

Bernardi A, Spahr PF. 1972. Nucleotide sequence at the binding site for coat protein on RNA of bacteriophage R17. Proc Natl Acad Sci 69: 3033-3037.

Boucher N, Wu Y, Dumas C, Dube M, Sereno D, Breton M, Papadopoulou B. 2002. A common mechanism of stage-regulated gene expression in Leishmania mediated by a conserved $3^{\prime}$ - untranslated region element. J Biol Chem 277: 19511-19520. 
Bringaud F, Müller M, Cerqueira GC, Smith M, Rochette A, ElSayed NMA, Papadopoulou B, Ghedin E. 2007. Members of a large retroposon family are determinants of post-transcriptional gene expression in Leishmania. PLoS Pathog 3: e136.

Bringaud F, Ghedin E, El-Sayed NM, Papadopoulou B. 2008. Role of transposable elements in trypanosomatids. Microbes Infect 10: 575-581.

Buxbaum AR, Haimovich G, Singer RH. 2015. In the right place at the right time: visualizing and understanding mRNA localization. Nat Rev Mol Cell Biol 16: 95-109.

Cheong CG, Hall TM. 2006. Engineering RNA sequence specificity of Pumilio repeats. Proc Natl Acad Sci 103: 13635-13639.

Chritton JJ, Wickens M. 2010. Translational repression by PUF proteins in vitro. RNA 16: 1217-1225.

Clayton C. 2013. The regulation of trypanosome gene expression by RNA-binding proteins. PLoS Pathog 9: e1003680.

Clement SL, Lykke-Andersen J. 2008. A tethering approach to study proteins that activate mRNA turnover in human cells. Methods Mol Biol 419: 121-133.

Cooke A, Prigge A, Opperman L, Wickens M. 2011. Targeted translational regulation using the PUF protein family scaffold. Proc Natl Acad Sci 108: 15870-15875.

Dallagiovanna B, Correa A, Probst CM, Holetz F, Smircich P, de Aguiar AM, Mansur F, da Silva CV, Mortara RA, Garat B, et al. 2008. Functional genomic characterization of mRNAs associated with TcPUF6, a pumilio-like protein from Trypanosoma cruzi. J Biol Chem 283: 8266-8273.

Das A, Morales R, Banday M, Garcia S, Hao L, Cross GA, Estevez AM, Bellofatto V. 2012. The essential polysome-associated RNA-binding protein RBP42 targets mRNAs involved in Trypanosoma brucei energy metabolism. RNA 18: 1968-1983.

Delhi P, Queiroz R, Inchaustegui D, Carrington M, Clayton C. 2011. Is there a classical nonsense-mediated decay pathway in trypanosomes? PLoS One 6: e25112.

Desjeux P. 2004. Leishmaniasis: current situation and new perspectives. Comp Immunol Microbiol Infect Dis 27: 305-318.

D’Orso I, Frasch AC. 2001. TcUBP-1, a developmentally regulated Urich RNA-binding protein involved in selective mRNA destabilization in trypanosomes. J Biol Chem 276: 34801-34809.

Droll D, Minia I, Fadda A, Singh A, Stewart M, Queiroz R, Clayton C. 2013. Post-transcriptional regulation of the trypanosome heat shock response by a zinc finger protein. PLoS Pathog 9: e1003286.

Dupé A, Dumas C, Papadopoulou B. 2014. An Alba-domain protein contributes to the stage-regulated stability of amastin transcripts in Leishmania. Mol Microbiol 91: 548-561.

Erben ED, Fadda A, Lueong S, Hoheisel JD, Clayton C. 2014. A genomewide tethering screen reveals novel potential post-transcriptional regulators in Trypanosoma brucei. PLoS Pathog 10: e1004178.

Estévez AM. 2008. The RNA-binding protein TbDRBD3 regulates the stability of a specific subset of mRNAs in trypanosomes. Nucleic Acids Res 36: 4573-4586.

Garcia JF, Parker R. 2015. MS2 coat proteins bound to yeast mRNAs block $5^{\prime}$ to $3^{\prime}$ degradation and trap mRNA decay products: implications for the localization of mRNAs by MS2-MCP system. RNA 21: 1393-1395.

Goldstrohm AC, Hook BA, Seay DJ, Wickens M. 2006. PUF proteins bind Pop2p to regulate messenger RNAs. Nat Struct Mol Biol 13: 533-539.

Goldstrohm AC, Seay DJ, Hook BA, Wickens M. 2007. PUF protein-mediated deadenylation is catalyzed by Ccr4p. J Biol Chem 282: 109-114.

Haile S, Papadopoulou B. 2007. Developmental regulation of gene expression in trypanosomatid parasitic protozoa. Curr Opin Microbiol 10: 569-577.

Haile S, Dupe A, Papadopoulou B. 2008. Deadenylation-independent stage-specific mRNA degradation in Leishmania. Nucleic Acids Res 36: $1634-1644$.
Hook BA, Goldstrohm AC, Seay DJ, Wickens M. 2007. Two yeast PUF proteins negatively regulate a single mRNA. J Biol Chem 282: 15430-15438.

Ivens AC, Peacock CS, Worthey EA, Murphy L, Aggarwal G, Berriman M, Sisk E, Rajandream MA, Adlem E, Aert R, et al. 2005. The genome of the kinetoplastid parasite, Leishmania major. Science 309: 436-442.

Jha BA, Fadda A, Merce C, Mugo E, Droll D, Clayton C. 2014. Depletion of the Trypanosome Pumilio domain protein PUF2 or of some other essential proteins causes transcriptome changes related to coding region length. Eukaryot Cell 13: 664-674.

Jha BA, Gazestani VH, Yip CW, Salavati R. 2015. The DRBD13 RNA binding protein is involved in the insect-stage differentiation process of Trypanosoma brucei. FEBS Lett 589: 1966-1974.

Johansson HE, Liljas L, Uhlenbeck OC. 1997. RNA recognition by the MS2 phage coat protein. In Seminars in Virology, Vol. 8, pp. 176-185. Elsevier, NY.

Kadyrova LY, Habara Y, Lee TH, Wharton RP. 2007. Translational control of maternal Cyclin B mRNA by Nanos in the Drosophila germline. Development 134: 1519-1527.

Keryer-Bibens C, Barreau C, Osborne HB. 2008. Tethering of proteins to RNAs by bacteriophage proteins. Biol Cell 100: 125-138.

Kramer S. 2012. Developmental regulation of gene expression in the absence of transcriptional control: the case of kinetoplastids. Mol Biochem Parasitol 181: 61-72.

Lee D, Ohn T, Chiang YC, Quigley G, Yao G, Liu Y, Denis CL. 2010. PUF3 acceleration of deadenylation in vivo can operate independently of CCR4 activity, possibly involving effects on the PAB1mRNP structure. J Mol Biol 399: 562-575.

Li CH, Irmer H, Gudjonsdottir-Planck D, Freese S, Salm H, Haile S, Estevez AM, Clayton C. 2006. Roles of a Trypanosoma brucei $5^{\prime} \rightarrow 3^{\prime}$ exoribonuclease homolog in mRNA degradation. RNA 12: 2171-2186.

Lublin AL, Evans TC. 2007. The RNA-binding proteins PUF-5, PUF-6, and PUF-7 reveal multiple systems for maternal mRNA regulation during C. elegans oogenesis. Dev Biol 303: 635-649.

Luu VD, Brems S, Hoheisel JD, Burchmore R, Guilbride DL, Clayton C. 2006. Functional analysis of Trypanosoma brucei PUF1. Mol Biochem Parasitol 150: 340-349.

McNicoll F, Müller M, Cloutier S, Boilard N, Rochette A, Dubé M, Papadopoulou B. 2005. Distinct 3 '-untranslated region elements regulate stage-specific mRNA accumulation and translation in Leishmania. J Biol Chem 280: 35238-35246.

Michaeli S. 2011. Trans-splicing in trypanosomes: machinery and its impact on the parasite transcriptome. Future Microbiol 6: 459-474.

Miller MA, Olivas WM. 2011. Roles of Puf proteins in mRNA degradation and translation. Wiley Interdiscip Rev RNA 2: 471-492.

Miller MT, Higgin JJ, Hall TM. 2008. Basis of altered RNA-binding specificity by PUF proteins revealed by crystal structures of yeast Puf4p. Nat Struct Mol Biol 15: 397-402.

Müller M, Papadopoulou B. 2010. Stage-specific expression of the glycine cleavage complex subunits in Leishmania infantum. Mol Biochem Parasitol 170: 17-27.

Müller M, Padmanabhan PK, Papadopoulou B. 2010a. Selective inactivation of SIDER2 retroposon-mediated mRNA decay contributes to stage- and species-specific gene expression in Leishmania. Mol Microbiol 77: 471-491.

Müller M, Padmanabhan PK, Rochette A, Mukherjee D, Smith M, Dumas C, Papadopoulou B. 2010b. Rapid decay of unstable Leishmania mRNAs bearing a conserved retroposon signature $3^{\prime}$ UTR motif is initiated by a site-specific endonucleolytic cleavage without prior deadenylation. Nucleic Acids Res 38: 5867-5883.

Myler PJ, Audleman L, deVos T, Hixson G, Kiser P, Lemley C, Magness C, Rickel E, Sisk E, Sunkin S, et al. 1999. Leishmania major Friedlin chromosome 1 has an unusual distribution of protein-coding genes. Proc Natl Acad Sci 96: 2902-2906.

Nilsson D, Gunasekera K, Mani J, Osteras M, Farinelli L, Baerlocher L, Roditi I, Ochsenreiter T. 2010. Spliced leader trapping reveals 
widespread alternative splicing patterns in the highly dynamic transcriptome of Trypanosoma brucei. PLoS Pathog 6: e1001037.

Ouellette M, Papadopoulou B. 2009. Coordinated gene expression by post-transcriptional regulons in African trypanosomes. J Biol 8: 100.

Padmanabhan PK, Zghidi-Abouzid O, Samant M, Dumas C, Aguiar BG, Estaquier J, Papadopoulou B. 2016. DDX3 DEAD-box RNA helicase plays a central role in mitochondrial protein quality control in Leishmania. Cell Death Dis 7: e2406.

Papadopoulou B, Roy G, Ouellette M. 1992. A novel antifolate resistance gene on the amplified $\mathrm{H}$ circle of Leishmania. EMBO $J$ 11: 3601-3608.

Papadopoulou B, Roy G, Ouellette M. 1994. Autonomous replication of bacterial DNA plasmid oligomers in Leishmania. Mol Biochem Parasitol 65: 39-49.

Papadopoulou B, McNicoll F, Rochette A, Müller M, Dumas C, Chow C. 2008. Regulation of gene expression in Leishmania throughout a complex digenetic life cycle. In Leishmania after the genome (ed. Myler P, Fasel N). Caister Academic Press, UK.

Papadopoulou B, Müller-McNicoll M, Padmanabhan PK. 2015. Approaches for studying mRNA decay mediated by SIDER2 retroposons in Leishmania. Methods Mol Biol 1201: 123-142.

Park E, Gleghorn ML, Maquat LE. 2013. Staufen2 functions in Staufen1mediated mRNA decay by binding to itself and its paralog and promoting UPF1 helicase but not ATPase activity. Proc Natl Acad Sci 110: $405-412$.

Quenault T, Lithgow T, Traven A. 2011. PUF proteins: repression, activation and mRNA localization. Trends Cell Biol 21: 104-112.

Richard D, Leprohon P, Drummelsmith J, Ouellette M. 2004. Growth phase regulation of the main folate transporter of Leishmania infantum and its role in methotrexate resistance. J Biol Chem 279: 54494-54501.

Rochette A, Raymond F, Ubeda JM, Smith M, Messier N, Boisvert S, Rigault P, Corbeil J, Ouellette M, Papadopoulou B. 2008. Genome-wide gene expression profiling analysis of Leishmania major and Leishmania infantum developmental stages reveals substantial differences between the two species. BMC Genomics 9: 255.

Roux KJ, Kim DI, Raida M, Burke B. 2012. A promiscuous biotin ligase fusion protein identifies proximal and interacting proteins in mammalian cells. J Cell Biol 196: 801-810.

Sambrook J, Russell D. 2001. Molecular cloning: a laboratory manual. Cold Spring Harbor Laboratory Press, NY.

Schoenberg DR, Maquat LE. 2012. Regulation of cytoplasmic mRNA decay. Nat Rev Genet 13: 246-259.

Sereno D, Roy G, Lemesre JL, Papadopoulou B, Ouellette M. 2001. DNA transformation of Leishmania infantum axenic amastigotes and their use in drug screening. Antimicrob Agents Chemother 45: 1168-1173.
Siegel TN, Hekstra DR, Wang X, Dewell S, Cross GA. 2010. Genomewide analysis of mRNA abundance in two life-cycle stages of Trypanosoma brucei and identification of splicing and polyadenylation sites. Nucleic Acids Res 38: 4946-4957.

Singh A, Minia I, Droll D, Fadda A, Clayton C, Erben E. 2014. Trypanosome MKT1 and the RNA-binding protein $\mathrm{ZC} 3 \mathrm{H} 11$ : interactions and potential roles in post-transcriptional regulatory networks. Nucleic Acids Res 42: 4652-4668.

Smith M, Bringaud F, Papadopoulou B. 2009. Organization and evolution of two SIDER retroposon subfamilies and their impact on the Leishmania genome. BMC Genomics 10: 240.

Staals RH, Bronkhorst AW, Schilders G, Slomovic S, Schuster G, Heck AJ, Raijmakers R, Pruijn GJ. 2010. Dis3-like 1: a novel exoribonuclease associated with the human exosome. EMBO $J$ 29: 2358-2367.

Suh N, Crittenden SL, Goldstrohm A, Hook B, Thompson B, Wickens M, Kimble J. 2009. FBF and its dual control of gld-1 expression in the Caenorhabditis elegans germline. Genetics 181: $1249-1260$.

Ulbricht RJ, Olivas WM. 2008. Puflp acts in combination with other yeast Puf proteins to control mRNA stability. RNA 14: 246-262.

Van Etten J, Schagat TL, Hrit J, Weidmann CA, Brumbaugh J, Coon JJ, Goldstrohm AC. 2012. Human Pumilio proteins recruit multiple deadenylases to efficiently repress messenger RNAs. J Biol Chem 287: 36370-36383.

Wang X, McLachlan J, Zamore PD, Hall TM. 2002. Modular recognition of RNA by a human pumilio-homology domain. Cell 110: 501-512.

Wickens M, Bernstein DS, Kimble J, Parker R. 2002. A PUF family portrait: 3'UTR regulation as a way of life. Trends Genet 18: 150-157.

Wu Y, El Fakhry Y, Sereno D, Tamar S, Papadopoulou B. 2000. A new developmentally regulated gene family in Leishmania amastigotes encoding a homolog of amastin surface proteins. Mol Biochem Parasitol 110: 345-357.

Wu B, Chao JA, Singer RH. 2012. Fluorescence fluctuation spectroscopy enables quantitative imaging of single mRNAs in living cells. Biophys J 102: 2936-2944.

Wurst M, Seliger B, Jha BA, Klein C, Queiroz R, Clayton C. 2012. Expression of the RNA recognition motif protein RBP10 promotes a bloodstream-form transcript pattern in Trypanosoma brucei. Mol Microbiol 83: 1048-1063.

Yokoshi M, Li Q, Yamamoto M, Okada H, Suzuki Y, Kawahara Y. 2014. Direct binding of Ataxin-2 to distinct elements in $3^{\prime}$ UTRs promotes mRNA stability and protein expression. Mol Cell 55: 186-198.

Zhang B, Gallegos M, Puoti A, Durkin E, Fields S, Kimble J, Wickens MP. 1997. A conserved RNA-binding protein that regulates sexual fates in the C. elegans hermaphrodite germ line. Nature 390: $477-484$. 

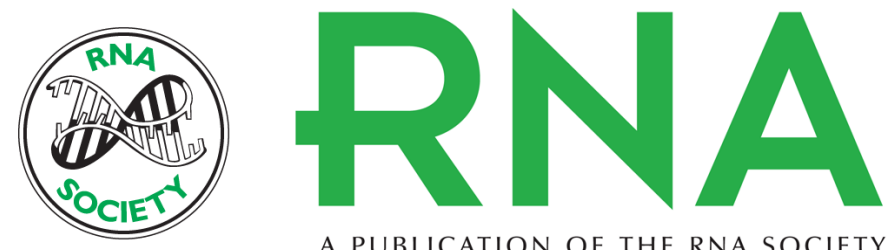

A PUBLICATION OF THE RNA SOCIETY

\section{The Pumilio-domain protein PUF6 contributes to SIDER2 retroposon-mediated mRNA decay in Leishmania}

Hiva Azizi, Carole Dumas and Barbara Papadopoulou

RNA 2017 23: 1874-1885 originally published online September 6, 2017

Access the most recent version at doi:10.1261/rna.062950.117

\section{Supplemental http://rnajournal.cshlp.org/content/suppl/2017/09/06/rna.062950.117.DC1 \\ Material}

References This article cites 75 articles, 25 of which can be accessed free at: http://rnajournal.cshlp.org/content/23/12/1874.full.html\#ref-list-1

Open Access Freely available online through the RNA Open Access option.

Creative This article, published in RNA, is available under a Creative Commons License Commons (Attribution 4.0 International), as described at

License http://creativecommons.org/licenses/by/4.0/.

Email Alerting Receive free email alerts when new articles cite this article - sign up in the box at the Service top right corner of the article or click here.

To subscribe to $R N A$ go to:

http://rnajournal.cshlp.org/subscriptions 